\title{
Aprontamentos sobre a (in)utilidade da Literatura
}

\author{
Maria Beatriz Almeida \\ Instituto de Literatura Comparada Margarida Losa
}

\begin{abstract}
Resumo: Num contexto em que as exigências pragmáticas de utilidade e eficiência determinam cada vez mais a ação humana, pensar e defender a literatura como forma de salvação do mundo adquire contornos quase utópicos. Partindo de provocações poéticas do último século, concentramo-nos em analisar como a literatura pode salvar um mundo globalizado como pré-experiência do mundo e do ser humano.
\end{abstract}

Palavras-chave: utilidade, crise, alteridade, literatura, anti-apocalíptico

\begin{abstract}
In a context in which the pragmatic requirements of utility and efficiency increasingly determine human action, thinking and defending literature as a way of saving the world acquires almost utopian contours. Based on contemporary poetic provocations, we focus on analyzing how literature can save a globalized world, both as a pre-experience of the world and of the human being.
\end{abstract}

Keywords: utility, crisis, alterity, literature, anti-apocalyptic

\section{Os poetas prestam contas ao Mundo}

Associar a literatura à salvação do mundo implica negar um dos pilares fundamentais dos estudos literários, segundo o qual a literatura é produzida sem nenhuma finalidade ou função utilitária pré-definida. Implica ainda suspender a consciência de que a literatura é enriquecida precisamente por esta falta apriorística de funções, descartar a infinidade de funções que ela desempenha no momento em que é lida. 
Neste contexto desvantajoso, procuramos o papel da literatura na salvação do mundo, o que se torna bastante árduo quando mesmo leitores insaciáveis como George Steiner afirmam:

[o] nazismo, o comunismo e o estalinismo convenceram-me deste paradoxo central: a cultura literária - expressão em desuso, mas ainda útil - a cultura literária, a literacia mais sofisticada, todas as técnicas de propaganda e transmissão cultural podem não só acompanhar a violência, a opressão e o despotismo, mas também, em certos pontos, reforçá-los. (Steiner in Serra/Soeiro 2018: 139)

Partilhando com Hegel a consciência de que todo o questionamento é uma procura, partiremos de algumas provocações poéticas sobre a utilidade da literatura, para depois mostrar como elas podem abrir caminho para uma salvação do mundo, mesmo numa sociedade cada vez mais crente na utilidade prática.

Referimo-nos aqui à salvação como o que nos livra de um perigo, de uma crise, de uma ameaça. Deste modo, admitir que a literatura e a arte em geral têm um papel a desempenhar na salvação do mundo implica aceitar que um mundo com literatura é melhor do que um sem ela. Tendo em conta que não existem evidências de um mundo sem literatura nos últimos milénios, esta premissa será aceite de bom grado.

Porém, o que nos perguntamos aqui é um pouco mais extremo: pode a literatura salvar o mundo? Uma primeira resposta, emoldurada pelas últimas crises sanitárias, políticas, climáticas, migratórias e humanitárias, parece ser negativa. Um poema não salva vidas, não acaba com a pobreza nem com a miséria humana, não impõe justiça na sociedade. Diretamente, num só passo (como hoje nos exigem: rápida e eficazmente) não pode. Esta constatação foi recentemente corroborada por poetas tão ativas como Ana Luísa Amaral' ou Matilde Campilho, ${ }^{2}$ e com toda a serenidade, sem sequer porem em causa o que a literatura pode efetivamente fazer. 0 facto de esta questão dilacerante ser uma preocupação de vários autores contemporâneos é digno de interesse, em particular quando escrevem, num tom quase explicativo:

Escute só

isto é um poema

não vai alinhar conceitos

do tipo liberdade igualdade e fé

Não vai ajeitar o cabelo

da menina que trabalha

com afinco na caixa registadora

do supermercado

Não vai melhorar

Não vai melhorar

(Campilho 2015: I0) 
O poema, na prática, não melhorou nada, seria escusado repeti-lo no final. Os três conceitos continuam tão difíceis de implementar no nosso mundo como dantes, a menina da caixa registadora terá o cabelo (e quem sabe a vida) desalinhado. Todavia, o poema torna-se antifrástico quando liberdade, igualdade e fé são alinhados num só verso. Ao negar assertivamente a incapacidade, a inutilidade do poema, abrem-se possibilidades para a ação humana no espírito do leitor, que confrontou pela primeira vez os três conceitos em coexistência linear. É-nos assim recordado o que nos mantém longe da utopia e talvez esta nova possibilidade nos incentive a transformar o mundo (por outros meios não poéticos): pelo menos, que tenhamos em mente o que ainda não está alinhado quando agimos no quotidiano, nos mais diversos âmbitos, e assim contribuamos para a salvação. Ao refletir sobre o conceito de mundo que usamos quando nos interrogamos sobre o papel da arte como salvadora, o que nos interessa é salvar o mundo presente, aquele em que vivemos, mas certamente não como o conhecemos. A constância não salva nada nem ninguém e cabe à literatura abrir os caminhos para a mudança.

Numa estratégia semelhante à de Campilho, Jorge Riechmann esclarece-nos humilde e provocadoramente:

\section{Un buen verso \\ no sacia el hambre. \\ Un buen verso \\ no construye un jardín.}

Un buen verso

no derriba al tirano.

Un verso

en el mejor de los casos consigue

cortarte la respiración

(la digestión casi nunca)

y su ritmo insinúa otro ritmo posible

para tu sangre y para los planetas.

(1990: 179)

Nestas estrofes, após três exemplos capitais de como a arte não pode salvar o mundo (não dessa forma imediata com que tantos sonham), é-nos recordado um outro tipo de salvação para o particular e para o universal. Podemos fazer deste outro ritmo possível o caminho para um mundo salvo, um primeiro alinhamento cósmico em 
direção à salvação do mundo? É uma leitura possível, especialmente tendo em conta que o agente de salvação nunca seria a palavra per se, mas o leitor. A menção a esta função única, e nem sempre cumprida - "en el mejor de los casos” - é suficiente para equilibrar a enumeração da incapacidade poética e abrir o caminho da transformação no leitor.

Como autor anti-apocalíptico, Italo Calvino preparou, em 1985, seis lições americanas, com seis propostas para o milénio seguinte, isto é, o nosso. A morte do autor ditou que só cinco fossem preparadas e nenhuma chegou a ser proferida na Universidade de Harvard. Não por acaso, acreditamos, as cinco que nos chegaram têm como título todas as características que hoje exigimos a um agente de salvação contemporâneo, por exemplo, a um computador: ligeireza, rapidez, exatidão, visibilidade e multiplicidade. De acordo com alguns rascunhos, a sexta lição seria dedicada à consistência e à correspondência entre o particular e o universal ou, como Jorge Riechmann o formulou, entre o sangue e os planetas. Estas características da literatura serviriam um milénio melhor, segundo uma análise feita não só por um autor canónico da literatura italiana, mas por quem resistiu contra o pior mal do século como partigiano antifascista. Também ele estava inquieto com todas as crises que se desenhavam já nos anos 80 e, contra todos as acusações da inutilidade da literatura, propõe-na antes como forma de salvação do mundo:

Alle volte mi sembra che un'epidemia pestilenziale abbia colpito l'umanità nella facoltà che più la caratterizza, cioè l'uso della parola, una peste del linguaggio che si manifesta come perdita di forza conoscitiva e di immediatezza, come automatismo che tende a livellare l'espressione sulle formule più generiche, anonime, astratte, a diluire i significati, a smussare le punte espressive, a spegnere ogni scintilla che sprizzi dallo scontro delle parole con nuove circostanze.

Non m'interessa qui chiedermi se le origini di quest'epidemia siano da ricercare nella politica, nell'ideologia, nell'uniformità burocratica, nell'omogeneizzazione dei mass-media, nella diffusione scolastica della media cultura. Quel che mi interessa sono le possibilità di salute. La letteratura (e forse solo la letteratura) può creare degli anticorpi che contrastino l'espandersi della peste del linguaggio. (Calvino 2002: ॥16)

[Por vezes, parece-me que uma epidemia pestilenta atingiu a humanidade na faculdade que mais a caracteriza, ou seja, o uso da palavra, uma praga da linguagem que se manifesta como perda de força cognitiva e imediatismo, como um automatismo que tende a nivelar a expressão nas fórmulas mais genéricas, anónimas, abstratas, a diluir os significados, a alisar as pontas expressivas, a apagar todas as centelhas que brotam do choque das palavras com as novas circunstâncias.

Aqui, não estou interessado em perguntar-me se as origens desta epidemia podem ser encontradas na política, na ideologia, na uniformidade burocrática, na homogeneização 
dos mass media, na disseminação escolar da cultura dos media. 0 que me interessa são as possibilidades de saúde. A literatura (e talvez só a literatura) pode criar anticorpos que neutralizam a propagação da praga da linguagem. (tradução nossa)]

É possível que esta associação entre literatura e antídoto nos pareça muito pertinente num período pandémico, mas mostra sobretudo como, em 1985, Calvino previa que a salvação do mundo podia passar por esta arte. 0 tom anti-apocalíptico do autor (não lhe interessam as causas, mas a cura) traduz-se numa crença das especificidades da literatura como tradução e conexão de experiências humanas, especificidades mais do que nunca necessárias quando queremos salvar o mundo. Porém, nós procuramos saber como (e não se) a literatura o pode fazer e a essa questão Calvino não responde totalmente.

Chegados a esta nova etapa interrogativa, podemos encontrar uma resposta mais detalhada numa muito kantiana crítica da razão apocalíptica, a que Michaël Fœssel deu o título Après la fin du monde. Nesta obra, o filósofo francês traça uma genealogia do catastrofismo da razão moderna, diagnostica a tendência atual para pensar o fim do mundo e explora ainda a experiência humana na sua capacidade de estranhar a contingência de tudo. Neste sentido, o mundo pode perder-se, mas não pode acabar, só se transforma. No âmbito desta reflexão, contorno propositadamente o núcleo filosófico da obra, que distingue entre o fim do mundo e a perda do mundo (Fœssel 2012: II0-166), para atentar num excerto em particular, no qual Fœssel se debruça sobre a ligação entre a metáfora e o mundo e assim nos ajuda a enquadrar uma (possível) forma de salvação do mundo através da arte:

C’est pourquoi les métaphores dont on se sert pour éclairer le monde disent quelque chose de ce que nous sommes. [...] Comme le montre la représentation scientifique du monde qui s'est imposée au début des Temps modernes, une image est le moyen par lequel les hommes prétendent savoir ce dont une chose retourne avant de se confronter avec elle. Une " image du monde » précède la manière dont les hommes font l'expérience des choses dans leur ensemble, tout comme, dans la physique moderne, les connaissances mathématiques précèdent leur application à la nature. (2012: 9)

[É por isso que as metáforas de que nos servimos para clarificar o mundo dizem algo do que somos. (...) Como demonstra a representação científica do mundo que se impôs no início da Modernidade, uma imagem é o meio pelo qual os homens fingem saber de onde vem uma coisa antes de se confrontar com ela. Uma «imagem do mundo» precede a forma como os homens fazem a experiência das coisas no seu todo, tal como, na física moderna, os conhecimentos matemáticos precedem a sua aplicação à natureza. (tradução nossa)] 
Neste excerto, encontramos uma possível e concreta função da arte no mundo e na sua salvação. Se as imagens do mundo propostas pela arte precedem a experiência que o homem tem dele, e podem determinar as suas ações sobre ele, se a arte prepara o Homem para o mundo, então pode, na prática, salvá-lo, e muito depende desta possibilidade.

Numa terceira e última provocação poética, a americana Adrienne Rich ironiza em torno desta ideia em “The burning of paper instead of children”.

\author{
What happens between us \\ has happened for centuries \\ we know it from literature \\ still it happens \\ sexual jealousy \\ outflung hand \\ beating bed \\ dryness of mouth \\ after panting \\ there are books that describe all this \\ and they are useless \\ (Rich 2018: 85-86)
}

$\mathrm{Na}$ constatação provocadora de uma inutilidade aparente da literatura, Adrienne Rich junta-se às vozes poéticas já citadas no início, embora o desenvolvimento do poema conduza o sujeito poético à conclusão oposta, como o título deixa prever. 0 exemplo, o que está em jogo no texto, o que existe na literatura e aconteceu depois antecipa-se à nossa experiência pessoal. E para quê, se vivemos o mundo com ou sem experiência prévia? Esta pré-experiência aparentemente inútil que a literatura nos permite revela-se bastante útil porque, ao preceder a experiência que fazemos do mundo, dá-nos tempo: permite-nos ponderar as ações que queremos implementar para mudá-lo... ou salvá-lo.

Muito do que se tem feito na literatura e noutras artes, frequentemente encaradas e usadas como plataforma de visibilidade para grandes problemas e injustiças sociais, uma vitrina da parte do mundo que precisa de ser salva, tem esta função em conta. Sem arte, a consciência de que determinados problemas do mundo existem e podem ser resolvidos seria bem diferente hoje, estaria entregue a meios de comunicação cuja fiabilidade se vai tornando cada mais reduzida, entregue a discursos padronizados e polarizados (também eles fruto da exigência de rapidez dos nossos dias). Esta ideia é realçada novamente por Matilde Campilho, quando confessa: 
Parece que a primavera do mundo é um trabalho em progresso mas o caminho até lá está sendo todo feito entre as veredas e entre os galhos de fogo de um gigante inverno No nosso tempo eu acreditava muito nas notícias e na televisão Hoje eu acredito tudo nas experiências que me contam os homens (Campilho 2015: II7)

A grande vantagem da arte como bolha dinâmica e socialmente atenta destaca-se mais do que nunca: em benefício da própria liberdade e da consequente exclusão dos circuitos mais sistematizados, a arte mantém-se um holofote sobre o que precisa de salvação. Em partes do mundo em que se censura a arte como forma livre de expressão, de protesto, ou sensibilização, este seu papel torna-se muito mais evidente. Seja como sinal de alertae de resistência contra crises a resolver, seja pelo prazer do reconhecimento e catarse, ou ainda como possibilidade de fuga de um mundo inconstante e austero (e assim correndo o risco de se tornar um refúgio, não levando os leitores a mudar absolutamente nada), a arte tem vários papéis a desempenhar na salvação do mundo. Hannah Arendt estava já consciente desta possibilidade quando, nos rascunhos de $O$ que É Política?, após a Segunda Guerra Mundial, anota: "Os únicos a acreditar ainda no mundo são os escritores e os artistas" (apud Coquio 2015). Propondo mundos salvos, por salvar ou em vias de salvação, a arte é o palco de experiências possíveis, dos caminhos que há a percorrer e nisso é profundamente anti-apocalíptica e resistente.

\section{Pré-experiência do Mundo, pré-experiência do Ser Humano}

Num contexto em que a literariedade, o uso surpreendente das palavras, não satisfaz as mentes mais pragmáticas enquanto justificação para a prática da literatura, encará-la como projeto de conhecimento dos seres humanos e do mundo é uma posição frequentemente defendida desde a segunda metade do século XX. Leitores e pensadores inquietos como Antoine Compagnon ou o já citado Italo Calvino afirmam que a literatura tem ainda algo a oferecer pelos seus próprios meios, mas às quais nem todos são sensíveis. No seu já clássico La Littérature pour quoi faire? (2006), Antoine Compagnon repete uma fórmula muito humanista de que só a literatura pode ser o repositório de um saber insubstituível sobre a natureza humana e as suas particularidades, além de nos tornar sensíveis ao facto dos outros serem muito diferentes de nós e os seus valores também. Partindo do mesmo argumento, Calvino associa o conhecimento do Outro à velocidade, num milénio que nos quer mais rápidos do que nunca:

Dato che in ognuna di queste conferenze mi sono proposto di raccomandare al prossimo millennio un valore che mi sta a cuore, oggi il valore che voglio raccomandare è proprio questo: in un'epoca in cui altri media velocissimi e di estesissimo raggio trionfano, e ri- 
schiano d'appiattire ogni comunicazione in una crosta uniforme e omogenea, la funzione della letteratura è la comunicazione tra ciò che è diverso in quanto è diverso, non ottundendone bensì esaltandone la differenza, secondo la vocazione propria del linguaggio scritto. (2002: 106-107)

[É por isso que as metáforas de que nos servimos para clarificar o mundo dizem algo do que somos. (...) Como demonstra a representação científica do mundo que se impôs no início da Modernidade, uma imagem é o meio pelo qual os homens fingem saber de onde vem uma coisa antes de se confrontar com ela. Uma «imagem do mundo» precede a forma como os homens fazem a experiência das coisas no seu todo, tal como, na física moderna, os conhecimentos matemáticos precedem a sua aplicação à natureza. (tradução nossa)]

Esta visão da literatura junta-se à voz de Compagnon na medida em que, se a literatura pode um dia salvar o mundo, ou levar os leitores a fazê-lo, será porque permitiu o diálogo entre o Eu e o Outro, porque não simplificou o que é diverso e, por isso mesmo, complexo. Porque nos deu uma imagem do mundo em que o Outro existe, me convoca, e com o qual tenho de lidar exatamente assim, no tempo devido Para Calvino, esta vocação da linguagem escrita sempre existiu, e serve como método válido de salvação do mundo, na medida em que se opõe aos discursos de ódio tão céleres dos nossos dias.

A literatura, vista como meio de transmissão de experiências humanas singulares, de cultivo da alteridade, que depois se articulam na pré-experiência que o homem faz do mundo, ajuda à criação de uma identidade autónoma, porque enriquecida de um caleidoscópio de vozes: é uma identidade que se abre ao Outro. Poderá esta abertura à alteridade já sublinhada por Montaigne (c. 1580: 2) desempenhar algum papel na salvação do mundo? Somos tentados a pensar que sim, se imaginarmos um conjunto de seres humanos reunidos no mesmo espaço (leia-se, no mesmo planeta globalizado). Estamos confiantes, como todos os autores evocados, de que uma via de solução comum seria encontrada hoje para muitas crises atuais, e com menos sofrimento humano, se mais pessoas tivessem feito esta pré-experiência individual da alteridade, que estivessem na posse deste "saber das particularidades" do Outro (Compagnon 2006). A literatura revela-se, de facto, mais do que nunca útil num mundo em que as diferentes culturas estão concentradas num planeta percetivelmente mais pequeno. O mútuo entendimento é essencial hoje, e extremamente facilitado pela literatura, que neste sentido adquire um valor não só instrumental, mas salvífico.

A discussão sobre a utilidade e a função da literatura no mundo hodierno assume uma forma demasiado extensa para poder ser esgotada nestas páginas. Todavia, é através da atenção dada aos seus fragmentos que poderemos aproximar-nos do impacto real desta arte no mundo que queremos salvar. Resta uma confiança na capacidade de a literatura "convocar a nossa humildade, [...] diminuir a nossa capacidade de indiferença”, e a constatação de que só os artistas deram forma, até hoje, à utopia. 


\section{Notas}

* Maria Beatriz Almeida nasceu em 1998 e licenciou-se em Línguas, Literaturas e Culturas (variante Francês/Alemão) na FLUP, em 2019. Foi bolseira do Mestrado Erasmus Mundus em Culturas Literárias Europeias entre 2019 e 2021 nas Universidades de Haute-Alsace e de Bolonha. Durante esse período, foi representante internacional dos estudantes Erasmus Mundus CLE e obteve o Diplôme Universitaire en Études Hélvétiques com uma dissertação sobre Anne Perrier. Colabora atualmente com a Spira na revitalização e divulgação do património cultural português.

'Este ensaio foi escrito no âmbito da investigação desenvolvida no Instituto de Literatura Comparada, Unidade I\&D financiada por Fundos Nacionais através da FCT - Fundação para a Ciência e para Tecnologia (UIDB/00500/2020).

\section{Bibliowebgrafia}

Amaral, Ana Luísa / Tatiana Faria (202I), < www.youtube.com/ watch?v=PFPwDrEorwU $>$ (último acesso em 26/12/2021).

Calvino, Italo (2002), Lezioni Americane, Milão, Mondadori.

Campilho, Matilde (2015), Jóquei, Lisboa, Edições Tinta-da-China.

-- / Mariano Marovatto, < www.youtube.com/ watch?v=V7WInHg4QY8 > (último acesso em 26/12/202I).

Compagnon, Antoine (2006), La littérature, pour quoi faire?, < https://books. openedition.org/cdf/524 > (último acesso em I4/II/202I).

Coquio, Catherine (2015), “D’un ton anti-apocalyptique: Après la fin du monde de Michaël Fœssel et Récit d'un désastre de Michaël Ferrier”, Écrire l'histoire, 15, <http://journals.openedition.org/elh/6IO > (último acesso em 26/12/2021).

Fœssel, Michaël (2012), Après la fin du monde. Critique de la raison apocalyptique, Paris, Seuil.

Montaigne, Michel de (c. 1580), “Des cannibales”, Les Essais, < https://litterae. pagesperso-orange.fr/textes-Iere/Cannibales-Montaigne.pdf > (último acesso em 26/I2/202I).

Rich, Adrienne (2018), “The burning of paper instead of children”, in 1950-2012 Selected Poems, Nova Iorque, W. W. Norton, 83-86.

Riechmann, Jorge (1990), Poesía Practicable, Madrid, Hiperión.

Serra, José Pedro / Ricardo Gil Soeiro (2018), George Steiner - Das Cinzas do Silêncio à Palavra de Fogo, Editora Exclamação, Porto. 